Article

\title{
The Effects of Structure Thickness, Air Gap Thickness and Silicon Type on the Performance of a Horizontal Electrothermal MEMS Microgripper
}

\author{
Marija Cauchi ${ }^{1, *(1)}$, Ivan Grech ${ }^{2}$, Bertram Mallia ${ }^{3}$, Pierluigi Mollicone ${ }^{1}(\mathbb{C}$ \\ and Nicholas Sammut ${ }^{2}$ \\ 1 Department of Mechanical Engineering, Faculty of Engineering, University of Malta, \\ MSD 2080 Msida, Malta; pierluigi.mollicone@um.edu.mt \\ 2 Department of Microelectronics and Nanoelectronics, Faculty of Information and Communication Technology, \\ University of Malta, MSD 2080 Msida, Malta; ivan.grech@um.edu.mt (I.G.); nicholas.sammut@um.edu.mt (N.S.) \\ 3 Department of Metallurgy and Materials Engineering, Faculty of Engineering, University of Malta, \\ MSD 2080 Msida, Malta; bertram.mallia@um.edu.mt \\ * Correspondence: mcauc03@um.edu.mt; Tel.: +356-2340-2023
}

Received: 20 June 2018; Accepted: 11 July 2018; Published: 15 July 2018

\begin{abstract}
The ongoing development of microelectromechanical systems (MEMS) over the past decades has made possible the achievement of high-precision micromanipulation within the micromanufacturing, microassembly and biomedical fields. This paper presents different design variants of a horizontal electrothermally actuated MEMS microgripper that are developed as microsystems to micromanipulate and study the deformability properties of human red blood cells (RBCs). The presented microgripper design variants are all based on the U-shape 'hot and cold arm' actuator configuration, and are fabricated using the commercially available Multi-User MEMS Processes (MUMPs ${ }^{\circledR}$ ) that are produced by MEMSCAP, Inc. (Durham, NC, USA) and that include both surface micromachined (PolyMUMPs ${ }^{\mathrm{TM}}$ ) and silicon-on-insulator (SOIMUMPs ${ }^{\mathrm{TM}}$ ) MEMS fabrication technologies. The studied microgripper design variants have the same in-plane geometry, with their main differences arising from the thickness of the fabricated structures, the consequent air gap separation between the structure and the substrate surface, as well as the intrinsic nature of the silicon material used. These factors are all inherent characteristics of the specific fabrication technologies used. PolyMUMPs ${ }^{\mathrm{TM}}$ utilises polycrystalline silicon structures that are composed of two free-standing, independently stackable structural layers, enabling the user to achieve structure thicknesses of $1.5 \mu \mathrm{m}, 2 \mu \mathrm{m}$ and $3.5 \mu \mathrm{m}$, respectively, whereas SOIMUMPs ${ }^{\mathrm{TM}}$ utilises a $25 \mu \mathrm{m}$ thick single crystal silicon structure having only one free-standing structural layer. The microgripper design variants are presented and compared in this work to investigate the effect of their differences on the temperature distribution and the achieved end-effector displacement. These design variants were analytically studied, as well as numerically modelled using finite element analysis where coupled electrothermomechanical simulations were carried out in CoventorWare ${ }^{\circledR}$ (Version 10, Coventor, Inc., Cary, NC, USA). Experimental results for the microgrippers' actuation under atmospheric pressure were obtained via optical microscopy studies for the PolyMUMPs ${ }^{\mathrm{TM}}$ structures, and they were found to be conforming with the predictions of the analytical and numerical models. The focus of this work is to identify which one of the studied design variants best optimises the microgripper's electrothermomechanical performance in terms of a sufficient lateral tip displacement, minimum out-of-plane displacement at the arm tips and good heat transfer to limit the temperature at the cell gripping zone, as required for the deformability study of RBCs.
\end{abstract}

Keywords: MEMS microgrippers; micromanipulation; red blood cells; electrothermal actuation; PolyMUMPs ${ }^{\mathrm{TM}}$; SOIMUMPs ${ }^{\mathrm{TM}}$; structure thickness; air gap thickness; polysilicon; single crystal silicon 


\section{Introduction}

The constantly growing need for high-precision micromanipulation has seen the implementation of microelectromechanical systems (MEMS) in numerous applications within the micromanufacturing and biomedical fields. Microgrippers are one such type of MEMS devices that are typically designed to safely manipulate biological cells [1-9] as well as micromechanical parts [10-12]. The successful development of a MEMS microgripper depends on taking into account several factors including the design and mechanical structure [13], the actuation mechanism [14,15], the choice of materials used [16-19], the operational requirements and limitations [20], the fabrication technology [21-26], and the environment in which the microgripper will be operated [27].

Our previous work [25] presented an analytical and a numerical model of a horizontal electrothermal microgripper design that were developed to reliably predict the temperature distribution and displacement at the arm tips when operated under atmospheric pressure. These developed models focused on an electrothermomechanical analysis which considered heat conduction to the substrate, through both the air gap and the anchor pads, as the main source of heat loss from the structure. Tip displacement results obtained from the analytical and numerical models were comparable with the results obtained from the experimental testing performed on a fabricated PolyMUMPs ${ }^{\mathrm{TM}}$ structure. The main contribution of the current work consists of utilising the models established and validated in [25] to evaluate and compare the temperature and displacement behaviour of four electrothermal microgripper design variants. These microgripper design variants have the same in-plane geometry, with their main differences being the device thickness, the air gap thickness between the structure and the substrate surface, and the intrinsic nature of the silicon material, all of which are characteristics of the fabrication technologies used. In this regard, the current study investigates the feasibility of two commercially available fabrication technologies_PolyMUMPs ${ }^{\mathrm{TM}}$ and SOIMUMPs ${ }^{\mathrm{TM}}$ — to realise a microgripper structure with optimised electrothermomechanical performance. The electrothermomechanical performance is optimised based on the requirements to micromanipulate and study the deformability properties of human red blood cells (RBCs), and focuses on obtaining a sufficient opening stroke of the microgripper arms, minimum out-of-plane displacement at the arm tips and minimum temperature rise at the cell gripping zone.

RBCs, with a diameter of around $8 \mu \mathrm{m}$ and an approximate thickness of $2 \mu \mathrm{m}$, have an average lifetime of 120 days. They are responsible for carrying oxygen, and carbon dioxide $\left(\mathrm{CO}_{2}\right)$, from the lungs to the body tissues and back, respectively. Healthy and diseased RBCs differ in their deformability properties. Healthy RBCs are capable of undergoing the necessary cellular deformation to flow even through human microcirculation vessels with small diameters, thus being able to continuously fulfill their function of supplying oxygen to the biological tissues. However, studies have shown that a number of pathological conditions such as diabetes, sickle cell anemia, malaria and other genetic disorders negatively impact the deformability properties of RBCs [28,29]. The increased cell membrane stiffness in the presence of such pathological conditions inhibits the cellular deformation required for RBCs to freely flow through the smaller blood vessels, thus preventing RBCs from performing their important function. In the case of healthy cells, the required gripping force will be of the order of a few microNewtons, with this force expected to increase to achieve the same cell deformation in diseased cells due to the increased membrane stiffness. The deformability properties of RBCs can thus be an important measure of human well-being and their measurement has in fact been the subject of various studies over the years [30,31].

This paper investigates the effects of the structure thickness, the air gap thickness, and the different sources of silicon on the performance of a horizontal electrothermal microgripper designed for the deformability study of RBCs. The implemented 'hot and cold arm' microgripper design variants and the electrothermal actuation principle are defined in Section 2. Section 3 presents and compares the commercially available surface and bulk micromachining processes whose feasibility is studied for the fabrication of the considered microgripper design variants. The developed microgripper numerical models were simulated based on the finite element analysis (FEA) modelling technique and are described in Section 4. Section 5 outlines the setup used for the experimental investigation of 
the fabricated microgrippers that was carried out using optical microscopy. Section 6 presents and compares the electrical, thermal and mechanical performance of the different microgripper design variants, and finally, Section 7 highlights the concluding remarks and outcomes of this work.

\section{Microgripper Design Variants and Principle of Operation}

The microgripper design variants developed in this study are all derived from the U-shape 'hot and cold arm' electrothermal actuator configuration [32]. A 'hot and cold arm' actuator design is mainly composed of two parallel arms with dissimilar widths, the hot arm and the cold arm, that underlie the operating principle of the electrothermal actuator, and a flexure component that allows the actuator to bend and to achieve the required motion. Figure 1 demonstrates how two such actuators can form a complete microgripper, with the extending microgripper arms amplifying the achieved tip displacement. The 'hot and cold arm' microgripper design considered here consists of a kinematically simple structure that can be manufactured with a limited number of fabrication steps. Such a structure makes it easy to assess the feasibility of two commercially available fabrication processes as well as to study the effects of basic design parameters such as structure thickness, air gap thickness and silicon type on the performance of a microgripper for the intended application of RBC manipulation.

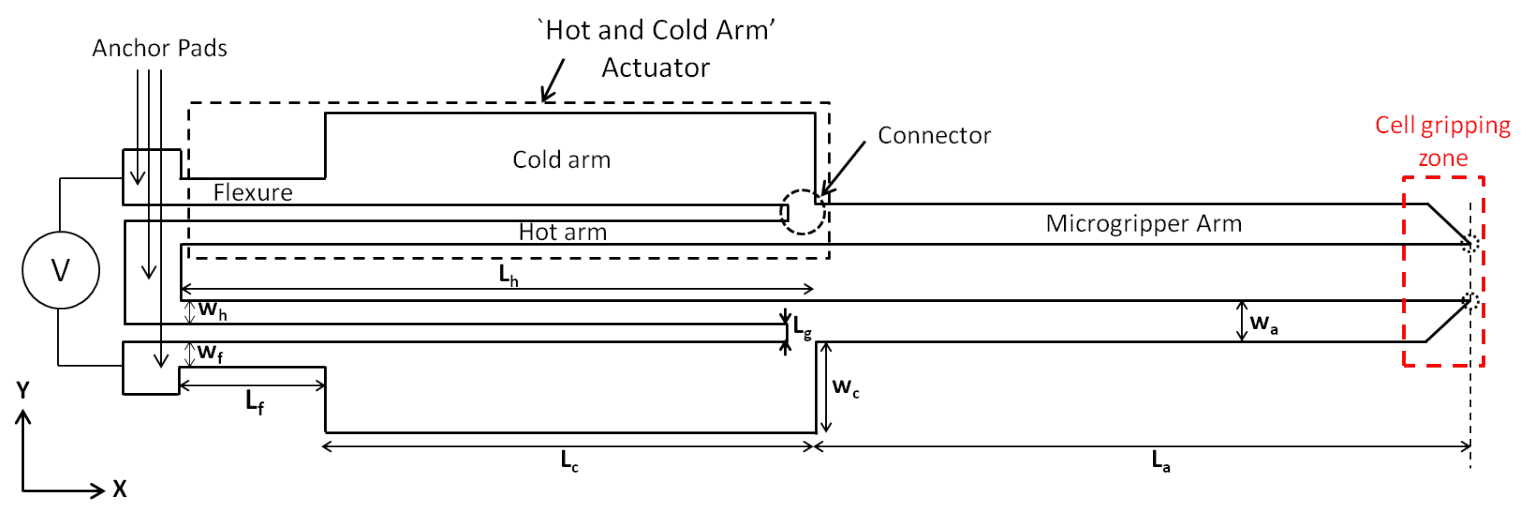

Figure 1. Schematic illustration of the electrothermal microgripper design based on the U-shape 'hot and cold arm' actuator configuration. The encircled points within the cell gripping zone indicate the arm tip points that will be later investigated for their $x-, y$ - and $z$-displacements. The cell gripping zone is to undergo further development in future work.

Under an applied potential, the hot and cold arms experience unequal resistive heating due to their different cross-sectional areas, and the resulting asymmetric thermal expansions result in a bending moment and in angular rotation of the arms about the fixed anchor pads. This motion drives the two gripping arms to open and close as necessary, and results in non-parallel gripping of the micro-object. The relative rotation angle for the opening motion of the arms is given by the inverse tangent of the ratio of the arm tip's displacement to the combined length of the hot arm and the microgripper arm $\left(L_{h}+L_{a}\right)$. In scenarios where parallel gripping is essential, a different kinematic design will be required [33]. There is, however, no requirement for non-parallel gripping in the case of RBC manipulation as RBCs are highly deformable and thus this non-parallel gripping is not expected to hinder their manipulation and deformability characterisation. Moreover, the same designed microgripper will be used to comparatively study the deformability properties of different RBCs, and hence the non-parallel gripping effect will not influence the results obtained.

The optimal design of flexure hinges in microgripper structures has been investigated in multiple works [34-38]. In the 'hot and cold arm' design, the ratio of the flexure length to the hot arm length is one of the design parameters that influences the maximum deflection achieved at the microgripper arm tips. This length ratio was optimised in the authors' previous work [32] and was found to have a value of 0.23 . Moreover, the flexure is generally manufactured to have the same width as the hot arm, 
which is in turn usually designed with the smallest dimension that the fabrication process is capable of achieving. The flexure is, however, much shorter than the hot arm, thus limiting its temperature from increasing to the same degree as that of the hot arm. These length and width criteria ascertain that the flexure is designed with the correct dimensions to effectively operate as a low-stiffness extension of the cold arm, ensuring proper elastic deflection of the actuator. As for the entire microgripper structure, the thickness of the flexure in this work is dependent on the fabrication process.

The performance of a microgripper is largely dependent on its geometry and dimensional parameters, as well as its material properties. This work focuses on four microgripper design variants that have the same dimensions in the $x$-y plane (i.e., the length and width parameters), but different structure and air gap thicknesses, as well as different material properties. The fixed length and width parameters of the designed microgrippers are given in Table 1.

Table 1. Fixed geometrical dimensions of the studied microgripper design variants. The dimension annotations are given in Figure 1.

\begin{tabular}{lcc}
\hline Parameter & Value & Unit \\
\hline Length of hot arm, $L_{h}$ & 200 & $\mu \mathrm{m}$ \\
Length of cold arm, $L_{c}$ & 154 & $\mu \mathrm{m}$ \\
Length of flexure, $L_{f}$ & 46 & $\mu \mathrm{m}$ \\
Length of connector, $L_{g}$ & 3 & $\mu \mathrm{m}$ \\
Length of gripping arm, $L_{a}$ & 203 & $\mu \mathrm{m}$ \\
Width of hot arm, $w_{h}$ & 3 & $\mu \mathrm{m}$ \\
Width of cold arm, $w_{c}$ & 14 & $\mu \mathrm{m}$ \\
Width of flexure, $w_{f}$ & 3 & $\mu \mathrm{m}$ \\
Width of gripping arm, $w_{a}$ & 6 & $\mu \mathrm{m}$ \\
\hline
\end{tabular}

The differences in structure thickness, air gap thickness, and material type of the four microgripper design variants were achieved by making use of different fabrication technologies: three designs were obtained using the different structural layers offered by the PolyMUMPs ${ }^{\mathrm{TM}}$ process, and one design was obtained using the SOIMUMPs ${ }^{\mathrm{TM}}$ process. These two fabrication technologies have very different sources of silicon, mainly low pressure chemical vapour deposition (LPCVD) for polycrystalline silicon films for the PolyMUMPs ${ }^{\mathrm{TM}}$ process, and mechanically-thinned wafers of single crystal silicon (SCS) for the SOIMUMPs ${ }^{\mathrm{TM}}$ process, resulting in different material properties. SOIMUMPs ${ }^{\mathrm{TM}}$ utilises a $25 \mu \mathrm{m}$ thick SCS structure having only one free-standing structural layer, whereas PolyMUMPs ${ }^{\mathrm{TM}}$ utilises polysilicon structures with thicknesses in the range of micrometers that are made from two free-standing, independently stackable structural layers. Although the individual sacrificial and structural layer thicknesses are determined by the PolyMUMPs ${ }^{\mathrm{TM}}$ fabrication process, three design variants with different thickness dimensions have been fabricated by using the two available structural layers individually as well as by fabricating a stack of both layers, enabling the user to achieve structure thicknesses of $1.5 \mu \mathrm{m}, 2 \mu \mathrm{m}$ and $3.5 \mu \mathrm{m}$ with the same process. These two structural layers are both made of polysilicon but are subject to a different amount of diffusion-doping with phosphorus, leading to different values for the electrical resistivity of the two layers. For the same in-plane geometry, the different structural thicknesses result in a wide range of aspect ratio (width:thickness) values, from a value of 30 for the $1.5 \mu \mathrm{m}$ thick PolyMUMPs ${ }^{\mathrm{TM}}$ structure down to a value of 1.8 for the $25 \mu \mathrm{m}$ thick SOIMUMPs ${ }^{\mathrm{TM}}$ structure. Moreover, the different thicknesses of the PolyMUMPs ${ }^{\mathrm{TM}}$ structures also result in different air gap separations between the device and the substrate, while no small air gap is present in the SOIMUMPs ${ }^{\mathrm{TM}}$ structure.

\section{Fabrication Processes}

The PolyMUMPs ${ }^{\mathrm{TM}}$ and SOIMUMPs ${ }^{\mathrm{TM}}$ fabrication technologies are both standard, commercially available Multi-User MEMS Processes (MUMPs $\left.{ }^{\circledR}\right)$ that are produced by MEMSCAP, Inc.

PolyMUMPs $^{\mathrm{TM}}$ [39] is a surface micromachining process that utilises a $20 \mu \mathrm{m}$ thick (100) SCS handle wafer (known as Substrate), a silicon nitride layer for electrical isolation (known as Nitride), 
three mechanical layers of LPCVD polysilicon (known as Poly-0, Poly-1 and Poly-2), two sacrificial layers of LPCVD phosphosilicate glass (PSG) (known as Oxide-1 and Oxide-2), and a layer of gold with a thin chromium adhesion layer (known as Metal) that are deposited by electron beam for probing, bonding, or electrical routing. Once the layers are photolitographically patterned and reactive ion etched, the PolyMUMPs ${ }^{\mathrm{TM}}$ process results in a suspended structure, i.e., a structure that is separated by a small air gap from the surface of the substrate. Because of this small air gap between the device and the substrate, small bumps known as dimples are introduced underneath the polysilicon beam to reduce the contact surface area in case the beam bends towards the substrate. Such dimples thus help to minimise device stiction to the substrate that is driven by surface energy. The Poly- 1 and Poly-2 layers can be used individually or stacked on top of each other to create suspended movable structures that are released when the intermediate PSG layers are removed through etching with hydrofluoric (HF) solution, followed by supercritical $\mathrm{CO}_{2}$ drying.

On the other hand, SOIMUMPs ${ }^{\mathrm{TM}}$ [40] is a silicon-on-insulator (SOI) micromachining process that utilises a $400 \mu \mathrm{m}$ thick (100) SCS handle wafer (known as Substrate), a silicon dioxide layer for electrical isolation (known as Oxide), a SCS layer that is mechanically-thinned (known as SOI), and two layers of gold with a thin chromium adhesion layer (known as Pad-Metal and Blanket-Metal) that are deposited by electron beam. The $25 \mu \mathrm{m}$ thick SOI layer is mechanically released by jointly using an undercut etch with vapour phase HF acid to remove the Oxide layer, and deep reactive ion etching from the backside of the substrate layer (known as Trench), in this way creating an overhanging movable structure, i.e., a structure that is totally exposed to ambient with no small air gap present.

Figure 2 highlights the main dimensional differences resulting from the two fabrication processes. The main differences between structures fabricated with these two technologies are the different thickness of the released silicon layers $t$, the different air gap thickness $t_{a}$ or lack thereof, as well as the different structural material. Table 2 summarises the microgripper design variants studied in this work.

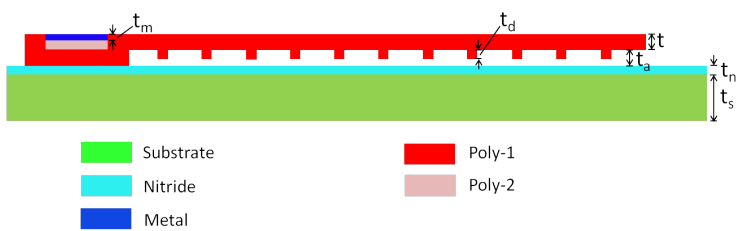

(a)

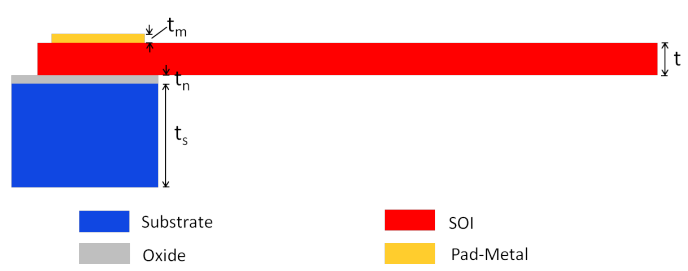

(b)

Figure 2. Cross-sectional schematic of the microgripper structure fabricated with the PolyMUMPs ${ }^{\mathrm{TM}}$ surface micromachining technology (a) and the SOIMUMPs ${ }^{\mathrm{TM}}$ bulk micromachining technology (b) (not-to-scale). Note that the PolyMUMPs ${ }^{\mathrm{TM}}$ process results in a suspended structure (i.e., with a small air gap between the device and the substrate) while the SOIMUMPs ${ }^{\mathrm{TM}}$ process results in an overhanging structure (i.e., the structure is totally exposed to ambient with no small air gap present).

Table 2. Design variants of the studied microgripper structure. The given nominal thicknesses are in $\mu \mathrm{m}$ and are annotated in Figure 2. The thickness parameters are defined by the respective fabrication process and the mask layers used.

\begin{tabular}{cccccccccc}
\hline Design Variant \# & $\boldsymbol{t}$ & $\boldsymbol{t}_{\boldsymbol{a}}$ & $\boldsymbol{t}_{\boldsymbol{d}}$ & $\boldsymbol{t}_{\boldsymbol{s}}$ & $\boldsymbol{t}_{\boldsymbol{n}}$ & $\boldsymbol{t}_{\boldsymbol{m}}$ & Process & Material & Mask Layer \\
\hline 1 & 1.5 & 2.75 & 2 & 20 & 0.6 & 0.5 & PolyMUMPs $^{\mathrm{TM}}$ & Polysilicon & Poly-2 \\
2 & 2 & 2 & 0.75 & 20 & 0.6 & 0.5 & PolyMUMPs $^{\mathrm{TM}}$ & Polysilicon & Poly-1 \\
3 & 3.5 & 2 & 0.75 & 20 & 0.6 & 0.5 & PolyMUMPs $^{\mathrm{TM}}$ & Polysilicon & Poly-1 + Poly-2 \\
4 & 25 & - & - & 400 & 2 & 0.5 & SOIMUMPs $^{\mathrm{TM}}$ & Single Crystal Silicon & SOI \\
\hline
\end{tabular}




\section{Numerical Models}

Numerical models based on the FEA technique were developed in CoventorWare ${ }^{\circledR}$ and used to sequentially compute the steady-state electrothermal and thermomechanical performance of the designed microgrippers. The models of the microgripper design variants fabricated with the PolyMUMPs ${ }^{\mathrm{TM}}$ process (Design Variants 1-3) and with the SOIMUMPs ${ }^{\mathrm{TM}}$ process (Design Variant 4) are shown in Figures 3 and 4, respectively. A parabolic tetrahedral mesh with an element size of $1 \mu \mathrm{m}$ was determined by a mesh refinement study to ensure an accurate and cost-effective mesh size. The numerical simulations were performed taking into account nonlinear geometry, while the influence of body forces such as gravity were not considered as they were found to be negligible at the microscale. The arm tip points indicated in Figure 1 were numerically investigated for their $x-, y-$, and $z$-displacements.

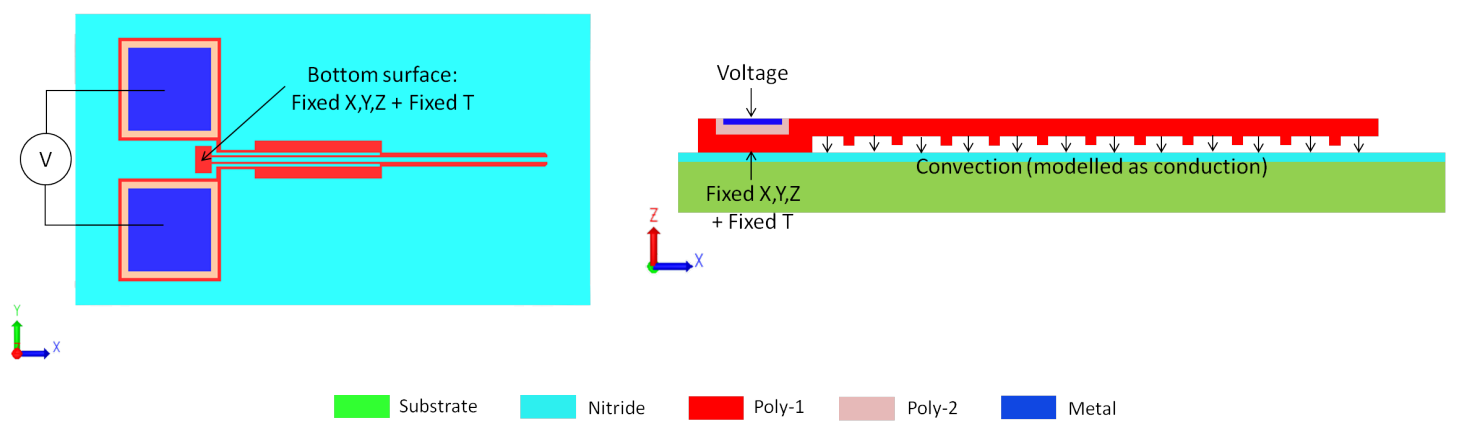

Figure 3. The suspended PolyMUMPs ${ }^{\mathrm{TM}}$ electrothermal microgripper as modelled in CoventorWare ${ }^{\circledR}$. This model represents the mechanical structure for Design Variants 1-3, and demonstrates the boundary conditions applied to the model.

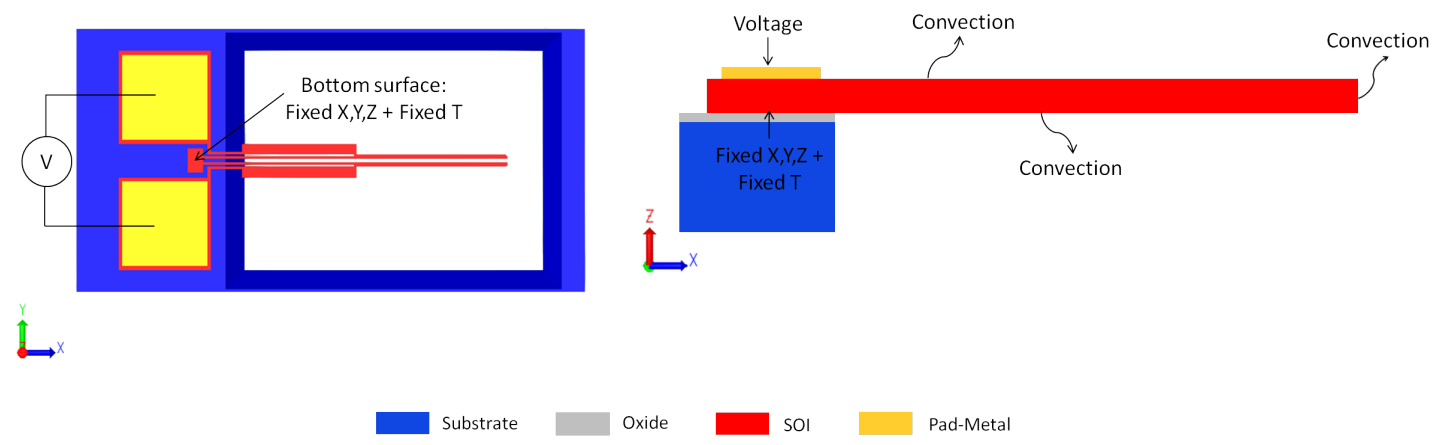

Figure 4. The overhanging SOIMUMPs ${ }^{\mathrm{TM}}$ electrothermal microgripper as modelled in CoventorWare ${ }^{\circledR}$. This model represents the mechanical structure for Design Variant 4, and demonstrates the boundary conditions applied to the model.

The material properties used within the numerical models are given in Table 3 and Figure 5. Isotropic properties are used for polycrystalline silicon. Polysilicon films with a $1 \mu \mathrm{m}$ thickness or larger are usually composed of relatively columnar grains with an average grain size of 300-600 nm across most of the film thickness and dominant $<100>$ texture. This grain size is strongly influenced by deposition parameters and annealing temperatures. Such a microstructure permits large polysilicon components composed of a large aggregate of grains, such as MEMS devices that are tens to hundreds of micrometers large, to be considered as transversely isotropic and under plane strain, locally and globally [41]. In the case of SCS, while thermal properties can be assumed to be isotropic for any given plane, the elastic and mechanical properties are, however, direction dependent. This variation results from the anisotropic nature of silicon whose crystalline structure exhibits cubic symmetry. The elastic behavior of silicon MEMS structures depends on the orientation of the structure with respect to the 
crystallographic axes. The (100) plane is the most common silicon wafer orientation used for the microfabrication of MEMS devices and thus the elasticity values of SCS are given in the frame of reference of a standard (100) silicon wafer in this work. Due to its cubic symmetry, it is possible to describe silicon as an orthotropic material and to give its elastic properties in terms of orthotropic material constants as shown in Table $3[42,43]$.

Table 3. Material properties extracted from the CoventorWare ${ }^{\circledR}$ Materials Library for the PolyMUMPs $^{\mathrm{TM}}$ [39] and SOIMUMPs ${ }^{\mathrm{TM}}$ [40] fabrication processes. Unless otherwise specified, these material properties are given at $300 \mathrm{~K}$.

\begin{tabular}{|c|c|c|c|c|c|}
\hline \multirow{2}{*}{ Property } & \multicolumn{3}{|c|}{ PolyMUMPs $^{\mathrm{TM}}$} & \multicolumn{2}{|c|}{ SOIMUMPs $^{\mathrm{TM}}$} \\
\hline & Poly1 & Poly2 & Metal & SOI & PadMetal \\
\hline Density $\left[\mathrm{g} /(\mathrm{cm})^{3}\right]$ & 2.23 & 2.23 & 19.30 & 2.50 & 19.30 \\
\hline \multirow{2}{*}{ Young's modulus, $E$ [GPa] } & \multirow{2}{*}{158} & \multirow{2}{*}{158} & \multirow{2}{*}{57} & $E_{x}=E_{y}=169$ & \multirow{2}{*}{57} \\
\hline & & & & $E_{z}=130$ & \\
\hline \multirow{2}{*}{ Shear modulus, G [GPa] } & \multirow{2}{*}{-} & \multirow[t]{2}{*}{ - } & \multirow{2}{*}{-} & $G_{y z}=G_{z x}=79.6$ & \multirow[t]{2}{*}{-} \\
\hline & & & & $G_{x y}=50.9$ & \\
\hline \multirow{2}{*}{ Poisson's ratio, $v$} & \multirow[t]{2}{*}{0.22} & \multirow[t]{2}{*}{0.22} & \multirow[t]{2}{*}{0.35} & $v_{y z}=0.36, v_{z x}=0.29$ & \multirow[t]{2}{*}{0.35} \\
\hline & & & & $v_{x y}=0.064$ & \\
\hline Thermal expansion coefficient, $\alpha[\mu \mathrm{m} / \mathrm{mK}]$ & 2.80 & 2.80 & Refer to Figure 5 & 2.50 & Refer to Figure 5 \\
\hline Specific heat capacity, $c[\mathrm{~J} / \mathrm{kgK}]$ & 712 & 712 & 128.7 & 712 & 128.7 \\
\hline Thermal conductivity, $k$ [W/mK] & 32 & 32 & 297 & 148 & 297 \\
\hline Electrical resistivity $[\mu \cdot \Omega \cdot \mathrm{m}]$ & 20 & 30 & $3.12 \times 10^{-2}$ & 500 & $2.86 \times 10^{-2}$ \\
\hline
\end{tabular}

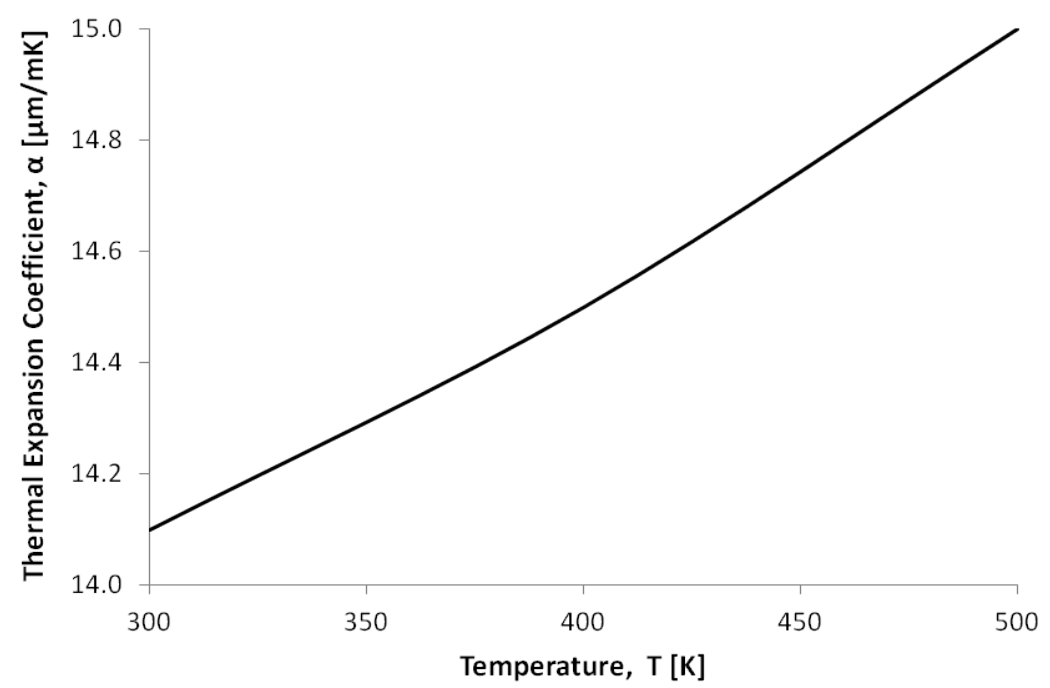

Figure 5. Variation of the coefficient of thermal expansion, $\alpha$, with temperature for the Metal and PadMetal Layers in the PolyMUMPs ${ }^{\mathrm{TM}}$ [39] and SOIMUMPs ${ }^{\mathrm{TM}}$ [40] processes, respectively.

The solution of the electrothermal and thermomechanical analyses also requires a number of boundary conditions to be applied within the models to define the electrical, thermal and mechanical constraints imposed on the system. The boundary conditions implemented within these models are indicated in Figures 3 and 4, and included applying the actuation voltage to the top surface of the metallised probe pads, setting an initial temperature as a volumetric boundary condition to all the model elements, fixing the temperature of the bottom surface of the three anchored pads to room temperature throughout the analyses since these pads are anchored to the substrate, which acts as a heat sink, and restricting the motion of the bottom surface of the three anchored pads in all directions 
throughout the analyses. All the above-mentioned boundary conditions were identically applied to the four microgripper design variants.

An additional boundary condition was then separately applied to the PolyMUMPs ${ }^{\mathrm{TM}}$ structures (Design Variants 1-3) and the SOIMUMPs ${ }^{\mathrm{TM}}$ structure (Design Variant 4 ) to simulate convective heat transfer. Due to the very small air gap, $t_{a}$, between the microgripper and the substrate resulting from the PolyMUMPs ${ }^{\mathrm{TM}}$ fabrication technology (Figure 2a), convection from the bottom surface of the microgripper to the substrate becomes significant, and other heat losses by natural convection from the other beam surfaces can justifiably be assumed to be comparatively negligible. Moreover, the small air gap permits the convective heat transfer coefficient of the bottom surface to be modelled by conduction through the air gap to the substrate [44]. This approach was thus applied to simulate heat losses in the numerical models for Design Variants 1-3. On the other hand, due to the absence of a small air gap beneath the overhanging SOIMUMPs ${ }^{\mathrm{TM}}$ structure (Figure $2 \mathrm{~b}$ ), there is no dominant convective heat loss from the bottom surface compared to the other beam surfaces and thus, in this case, a convective heat transfer coefficient was equally applied to all the beam surfaces in the numerical model for Design Variant 4 to simulate heat losses by natural convection in air. Moreover, heat losses by radiation can be reasonably ignored for thermal actuators operated at low operational power $[44,45]$ and were thus excluded from all the models in this work.

\section{Experimental Setup}

The experimental testing reported in this work was carried out on the microgripper structures fabricated with PolyMUMPs ${ }^{\mathrm{TM}}$ (Design Variants 1-3). Different laboratory procedures are in place to reliably test RBCs under atmospheric conditions [46], thus justifying actuation characterisation in air in this study. The probe pads of the released fabricated structures were ultrasonically wire-bonded to the contact pads of an integrated circuit (IC) package to facilitate testing. Voltage probes, each with an integrated positioning system in the $x-, y$ - and $z$-directions, were then used to electrically achieve a connection between the IC package and the power supply. Each microgripper structure based on Design Variants 1-3 was actuated by applying a potential in increments of 0.5 up to $3 \mathrm{~V}$ on each arm, in the meantime also taking note of the current through the structure. The thermal time constant of the studied microgripper design variants is of the order of milliseconds, and thus an interval of a few seconds between each voltage step ensured that steady-state conditions were obtained before applying the new voltage.

The relative opening displacement of each microgripper arm tip was measured at atmospheric pressure on a vibration isolation Cascade Microtech Summit 11,000/12,000 B-series probe station with an embedded optical microscope-based vision system. A Mitutoyo's Metallurgical Plan Apochromatic (M Plan APO) $10 \times$ objective lens, in conjunction with the $10 \times$ magnification of the eyepiece, was used for the experimental characterisation. The features of such an objective lens include infinity corrections, bright field observation, long working distance and corrections of chromatic and spherical aberrations. A tracking software program was used to automatically measure the relative opening stroke of each arm, from which the absolute total gap opening could then be calculated by taking into account the $5 \mu \mathrm{m}$ initial gap between the arm tips in the closed (i.e., not actuated) position. The width of the gripping arm $(6 \mu \mathrm{m})$ was taken as a reference for calibration. The experimental setup is shown in Figure 6. 


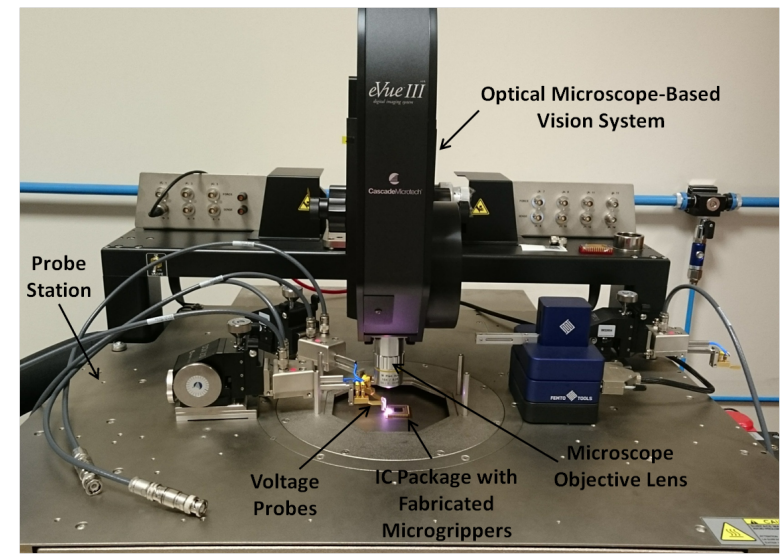

Figure 6. Experimental setup used to test the microgripper design variants fabricated with PolyMUMPs ${ }^{\mathrm{TM}}$. The microgripper structures are mounted on an integrated circuit package and actuated with voltage probes on the Cascade Microtech probe station [25].

\section{Results and Discussion}

The four microgripper design variants that differ in terms of the device thickness, the air gap thickness between the device and the substrate or the lack thereof, and the silicon type (polysilicon versus SCS) have been studied for their electrothermomechanical performance. This has been conducted analytically, numerically and experimentally for Design Variants 1-3, and analytically and numerically for Design Variant 4.

\subsection{Thermal Analyses}

The temperature distribution developed within the microgripper is one of the important factors to be considered in a microgripper design. The maximum temperature on the hot arm determines the microgripper's performance, but, at the same time, this temperature needs to be kept within the material limits to avoid the onset of material damage. Additionally, for specific applications in the biomedical field, the temperature at the microgripper arm tips needs to be kept as minimum as possible to ensure the manipulation of living cells and tissues without inducing any damage.

Thermal characterisation of the actuated microgripper structures was performed analytically and numerically in this work. Figure 7 compares the analytical results for the temperature distribution along the different actuator components for Design Variants 1-4. The temperature profiles along the hot arm $T_{h}(x)$, cold arm $T_{c}(x)$, and flexure $T_{f}(x)$ for these structures were calculated using Equations (1)-(3), respectively, as derived in [25]:

$$
\begin{aligned}
& T_{h}(x)=T_{H}+C_{1} e^{m_{h} x}+C_{2} e^{-m_{h} x}, \\
& T_{c}(x)=T_{C}+C_{3} e^{m_{c} x}+C_{4} e^{-m_{c} x}, \\
& T_{f}(x)=T_{F}+C_{5} e^{m_{f} x}+C_{6} e^{-m_{f} x},
\end{aligned}
$$

where $m_{h}, m_{c}$ and $m_{f}$ are to be calculated for the hot arm, cold arm and flexure, respectively, using:

$$
m=\sqrt{\frac{S}{k_{p} t R_{t}}}
$$

where $S$ is the shape factor that accounts for the impact of the shape of the hot arm/cold arm/flexure on heat conduction to the substrate, $k_{p}$ is the thermal conductivity of polysilicon, $t$ is the device thickness and $R_{t}$ is the thermal resistance between the polysilicon beam and the substrate. The constants $C_{1}$ to $C_{6}$ 
are calculated based upon the boundary conditions applied to the actuator structure as detailed in [25]. In the case of Design Variant 4, a very large air gap thickness of $400 \mu \mathrm{m}$ was used in the analytical model, in this way rendering heat conduction from the bottom surface of the device through the large air gap negligible as is the case for an overhanging structure.

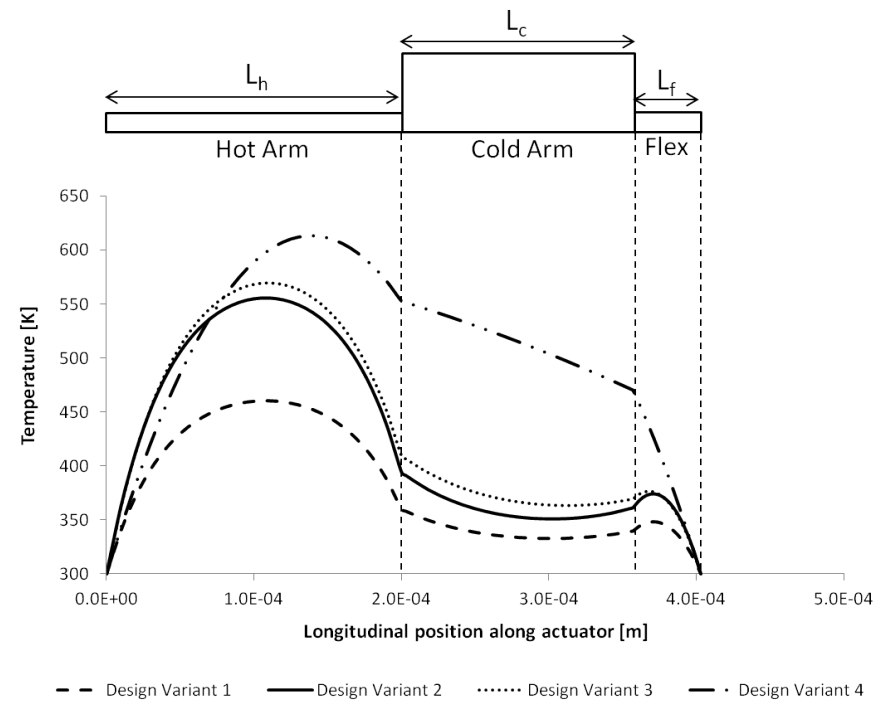

Figure 7. Comparison of the analytical results for the temperature profile along the hot arm, cold arm and flexure components of Design Variants 1-3 at $3 \mathrm{~V}$, and of Design Variant 4 at $14 \mathrm{~V}$. The diagram above the graph illustrates an unfolded thermal actuator without the extending microgripper arms.

The temperature distribution results obtained from the developed numerical models of the PolyMUMPs ${ }^{\mathrm{TM}}$ structures (Design Variants 1-3) and the SOIMUMPs ${ }^{\mathrm{TM}}$ structure (Design Variant 4) in CoventorWare ${ }^{\circledR}$ are given in Figures 8 and 9 , respectively.

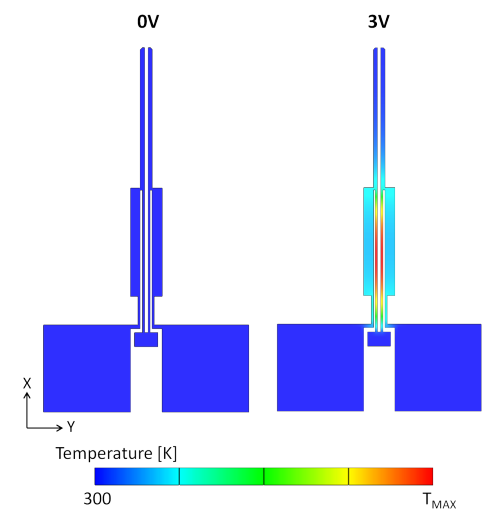

(a)

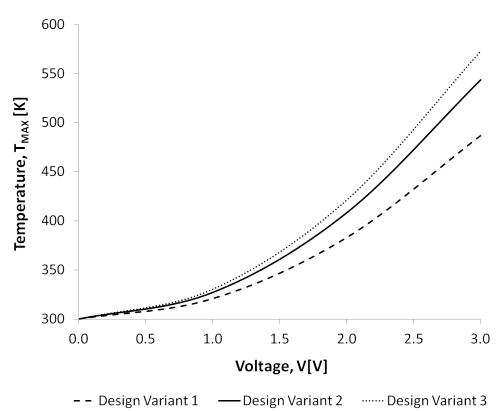

(b)

Figure 8. Simulated steady-state temperature distribution on the polysilicon microgripper structures fabricated with PolyMUMPs ${ }^{\mathrm{TM}}$ (Design Variants 1-3). The simulated plots in (a) show the temperature distribution with and without an applied potential for Design Variants 1-3. The maximum temperature of the actuated microgripper structure is located on the hot arm and is given by $T_{M A X}$, which is then quantified with applied potential in (b) for each specific design variant. 


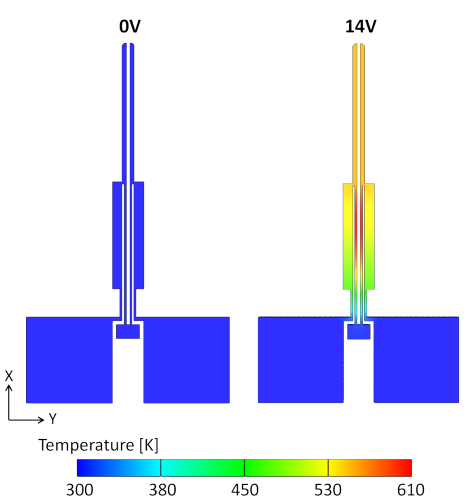

(a)

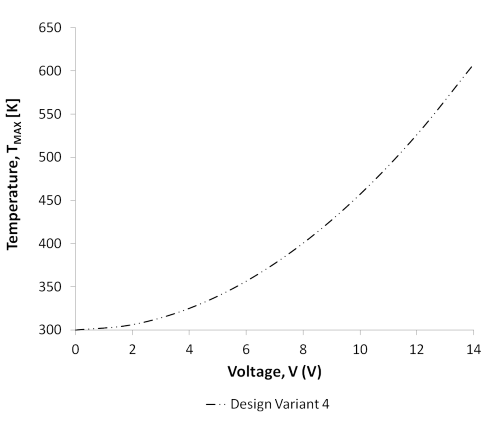

(b)

Figure 9. Simulated steady-state temperature distribution on the single crystal silicon microgripper structure fabricated with SOIMUMPs ${ }^{\mathrm{TM}}$ (Design Variant 4): simulated temperature plots showing the distribution with and without an applied potential (a), and variation of the maximum temperature, $T_{M A X}$, with applied potential (b). The maximum temperature, $\mathrm{T}_{M A X}$, of the actuated microgripper structure at $14 \mathrm{~V}$ is $610 \mathrm{~K}$ and is located on the hot arm as shown in (a).

It can be observed that, for each microgripper design variant, the maximum temperature is always located on the hot arm, independent of the structure thickness and the fabrication technology used (Figures 7, 8a and 9a). This is an inherent characteristic of the 'hot and cold arm' actuator design. In this design, the temperature difference between the hot and cold arms plays an important role in the achieved end-effector lateral displacement, with the latter increasing as the stated temperature difference increases for the same applied voltage. One way to maximise this temperature difference is to design the hot arm in such a way that its cross-sectional area is as small as possible considering the capability of the fabrication process. In the case of PolyMUMPs ${ }^{\mathrm{TM}}$ and SOIMUMPs ${ }^{\mathrm{TM}}$ fabrication technologies, the recommended minimum feature width is $3 \mu \mathrm{m}[39,40]$, which is, in fact, the value used for the width of the hot arm for the four microgripper design variants in this study (Table 1).

When considering the microgrippers fabricated with the PolyMUMPs ${ }^{\mathrm{TM}}$ technology (Design Variants 1-3), it can be observed that the most distinguished difference is between the temperature distribution of Design Variant 1, and that of Design Variants 2 and 3. The structure thickness, the air gap thickness and the intrinsic nature of the materials used (mainly in terms of the electrical resistivity property) all play a major role in defining the obtained temperature distribution on the microgripper structure. The maximum temperature developed on the hot arm increases with a thicker structure, a larger air gap thickness due to less heat lost by conduction through the air gap, and a smaller value for the electrical resistivity material property. When compared to Design Variants 2 and 3, Design Variant 1 has the smallest structure thickness of $1.5 \mu \mathrm{m}$, the largest air gap thickness of $2.75 \mu \mathrm{m}$ and the highest value for electrical resistivity (Table 3). The effects of the higher electrical resistivity value and the smaller structure thickness outweigh the effect of the larger air gap thickness, resulting in an overall reduction in the maximum temperature on the hot arm. The temperature distribution for Design Variants 2 and 3 is similar. These two microgripper design variants have the same air gap thickness $(2 \mu \mathrm{m})$, which affects the amount of heat lost by conduction to the substrate. The different thicknesses $(2 \mu \mathrm{m}$ for Design Variant 2 and $3.5 \mu \mathrm{m}$ for Design Variant 3) and electrical resistivities $(20 \mu \Omega \mathrm{m}$ for Design Variant 2 and $23.33 \mu \Omega \mathrm{m}$ for Design Variant 3) of the two structures almost balance out each other, resulting in a similar temperature distribution.

On comparing the temperature distribution of a surface micromachined structure (Design Variants 1-3) as given in Figures 7 and 8, to that of a bulk micromachined structure (Design Variant 4) as given in Figures 7 and 9, it can be observed that, despite the larger structure thickness and lack of a small air gap within the SOIMUMPs ${ }^{\mathrm{TM}}$ structure, the larger electrical resistivity value of SCS when compared to that of polysilicon (Table 3) results in greater power required to achieve a quantitatively 
similar temperature distribution to that obtained for the PolyMUMPs ${ }^{\mathrm{TM}}$ structures. It can be also observed from Figure 7 that the temperatures on the cold arm and the flexure are relatively high for Design Variant 4 when compared to those for Design Variants 1-3. This results in Design Variant 4 having the smallest temperature difference between the hot and cold arms, and, as stated previously, the larger this temperature difference, the larger will be the achieved end-effector lateral displacement. This small temperature difference will in fact cause the tips of Design Variant 4 to undergo the smallest opening stroke as will be shown in Section 6.2. Another interesting observation is that while the arm tips of the actuated PolyMUMPs ${ }^{\mathrm{TM}}$ structures remain at room temperature (Figure $8 \mathrm{a}$ ), this is not the case for the SOIMUMPs ${ }^{\mathrm{TM}}$ structure. It is shown in Figure 9a that the arm tips of the actuated SOIMUMPs ${ }^{\mathrm{TM}}$ microgripper undergo a rise in temperature due to the higher thermal conductivity of SCS when compared to that of polysilicon (Table 3). The lower thermal conductivity value of polycrystalline silicon is a result of the grain boundary scattering of phonons that governs the thermal resistance [47]. It must be ensured that the temperature rise at the arm tips is limited as much as possible to prevent damage to the studied RBCs.

\subsection{Structural Analyses}

A horizontal MEMS microgripper should always be designed such that it maximises the in-plane displacement and minimises the out-of-plane deflection at the microgripper am tips. The steady-state lateral displacement at the gripping arm tip, $u_{t i p}$, was calculated as a function of applied potential using Equation (5) as derived in [25]:

$$
u_{\text {tip }}=\frac{L_{h}{ }^{2}}{6 E I_{h}}\left(X_{1} L_{h}-3 X_{3}\right)+\frac{L_{a} L_{h}}{2 E I_{h}}\left(L_{h} X_{1}-2 X_{3}\right),
$$

where $L_{h}$ is the length of the hot arm, $E$ is the Young's modulus of polysilicon, $I_{h}$ is the moment of inertia for the hot arm, and $X_{1}, X_{2}$ and $X_{3}$ are the chosen redundant loads acting on the actuator structure. The force method [48] was applied to analyse the bending moment of the actuator due to these three redundant loads, which were calculated by solving the following set of simultaneous equations as detailed in [25]:

$$
\left[\begin{array}{lll}
f_{11} & f_{12} & f_{13} \\
f_{21} & f_{22} & f_{23} \\
f_{31} & f_{32} & f_{33}
\end{array}\right]\left[\begin{array}{l}
X_{1} \\
X_{2} \\
X_{3}
\end{array}\right]=\left[\begin{array}{c}
0 \\
\Delta L_{h}-\Delta L_{c}-\Delta L_{f} \\
0
\end{array}\right],
$$

where the terms $f_{i j}$ represent flexibility coefficients that define the deflection at $i$ due to a unit load at $j$. The flexibility coefficients are determined using Equation (7) where $m_{i}$ and $m_{j}$ represent the bending moments due to the respective three unit redundants $X_{1}, X_{2}$ and $X_{3}$ :

$$
f_{i j}=\int_{L} \frac{m_{i} m_{j}}{E I} d x .
$$

The relative opening stroke of each arm tip, calculated using Equation (5), is compared for Design Variants 1-4 in Figure 10. The steady-state in-plane and out-of-plane displacements are also obtained numerically with CoventorWare ${ }^{\circledR}$ for Design Variants 1-4 (Figures 11-13), and good agreement is observed for the obtained in-plane displacement between the analytical and numerical results. The current and power dissipated across each microgripper arm of Design Variants 1-4 with applied voltage are given in Figure 14. 


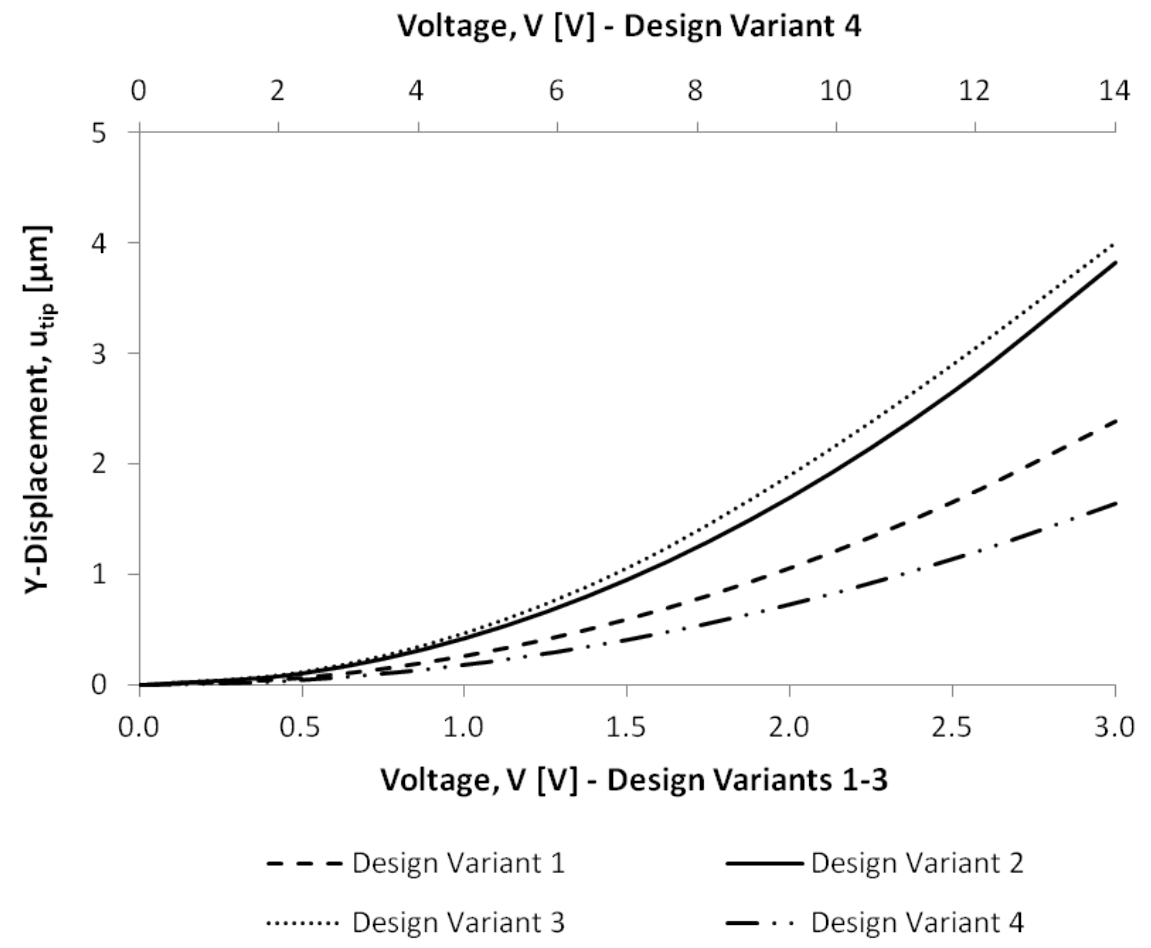

Figure 10. Analytical results for the variation of the relative $y$-displacement of the arm tip, $u_{\text {tip }}$, with applied voltage for Design Variants 1-4.

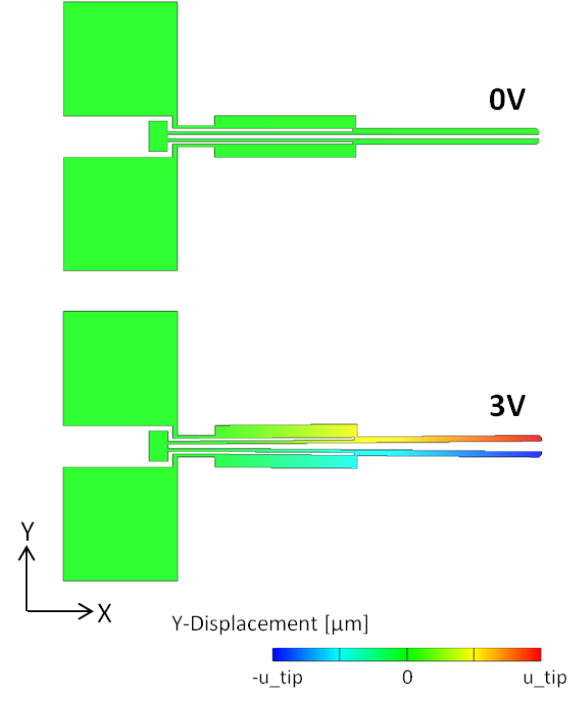

(a)

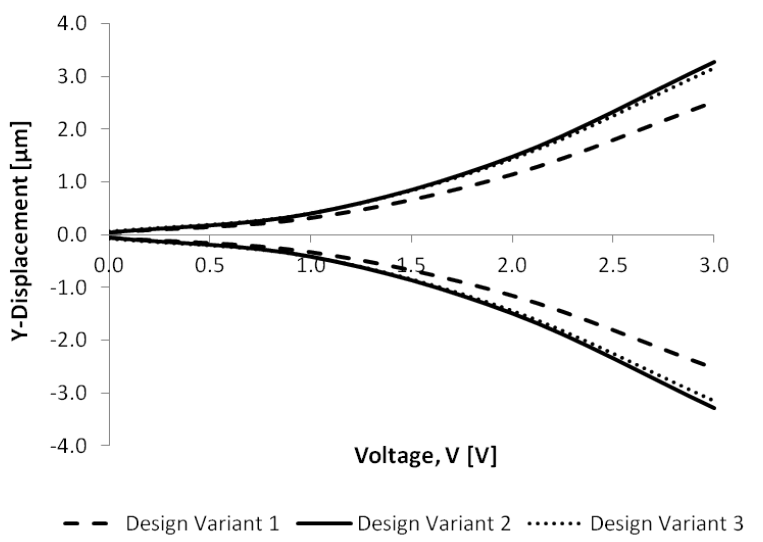

(b)

Figure 11. Simulated steady-state lateral displacement distribution on the polysilicon microgripper structures fabricated with PolyMUMPs ${ }^{\text {TM }}$ (Design Variants 1-3). The simulated plots in (a) show the $y$-displacement distribution with and without an applied potential for Design Variants 1-3. The absolute gap opening in the closed position (i.e., when not actuated), $u_{0}$, is $5 \mu \mathrm{m}$ with this absolute gap increasing to $u_{0}+2 u_{\text {tip }}$ when actuated. The relative opening stroke of each microgripper arm tip is then quantified with applied potential in (b) for each specific design variant. 


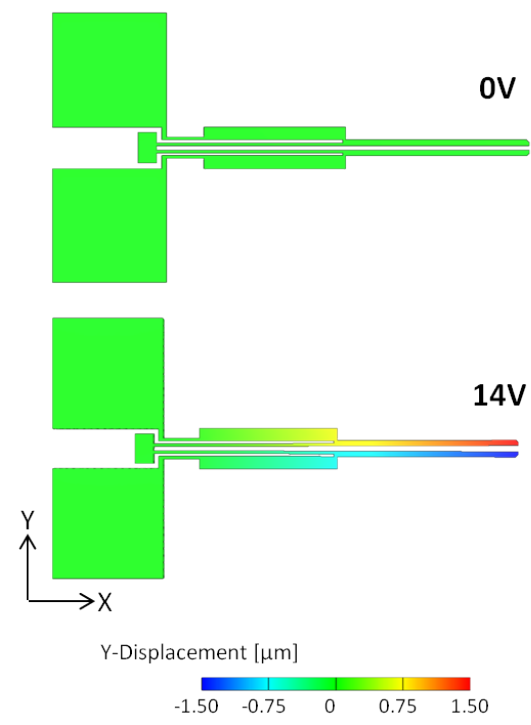

(a)

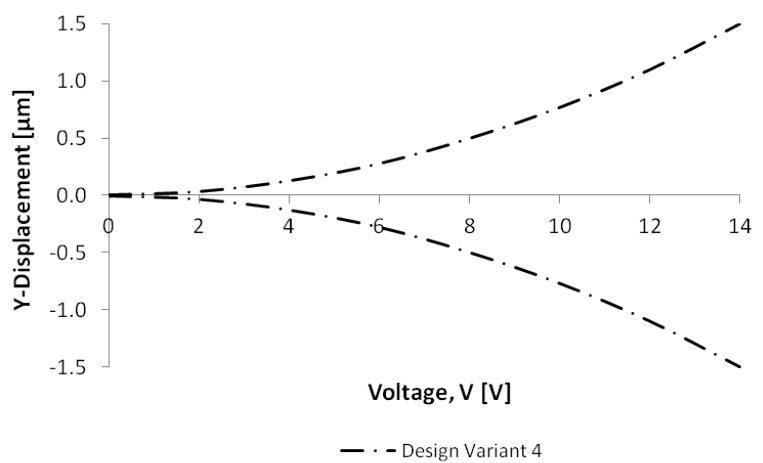

(b)

Figure 12. Simulated steady-state lateral displacement distribution on the single crystal silicon microgripper structure fabricated with SOIMUMPs ${ }^{\text {TM }}$ (Design 4): simulated $y$-displacement plots showing the distribution with and without an applied potential (a); and variation of the relative opening stroke of each microgripper arm tip with applied voltage (b). The absolute gap opening in the closed position is $5 \mu \mathrm{m}$ with this absolute gap increasing to $8 \mu \mathrm{m}$ at $14 \mathrm{~V}$.

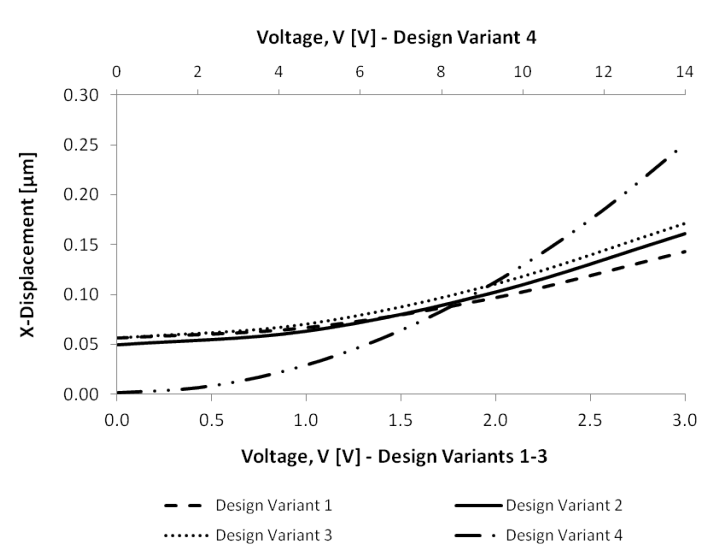

(a)

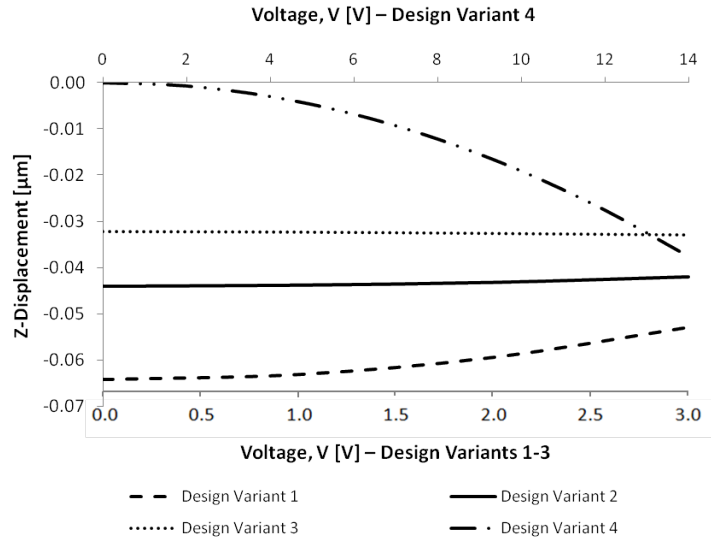

(b)

Figure 13. Simulated steady-state displacement profiles of Design Variants 1-4 with applied potential: $x$-displacement (forward displacement) of the microgripper arm tips (a); and $z$-displacement (out-of-plane displacement) of the microgripper arm tips (b).

On comparing the relative arm lateral displacements of Design Variants 1-4 (Figures 10-12), it is evident that Design Variant 4 undergoes the smallest opening stroke when actuated. In the case of Design Variant 4, the total gap opening is analytically and numerically predicted to be around $8 \mu \mathrm{m}$ at an applied potential of $14 \mathrm{~V}$, which is just in line with the design requirement of gripping a RBC. On the other hand, Design Variants 1-3 exceed the basic requirement of $8 \mu \mathrm{m}$ for the absolute gap opening between the arm tips. Despite this, it can be observed that SOIMUMPs ${ }^{\mathrm{TM}}$ structures require much greater power than PolyMUMPs ${ }^{\mathrm{TM}}$ structures (Figure 14) to achieve the intended motion. Another important observation is the difference in out-of-plane displacement ( $z$-displacement) at $0 \mathrm{~V}$ for Design Variants 1-4 (Figure 13b). This difference can be attributed to the inherent greater thickness 
and lower aspect ratio (width:thickness) fabrication of SOIMUMPs ${ }^{\mathrm{TM}}$ structures when compared to PolyMUMPs ${ }^{\mathrm{TM}}$ structures. The aspect ratio for PolyMUMPs ${ }^{\mathrm{TM}}$ structures depends on the layers used, but it is always much larger than the aspect ratio for SOIMUMPs ${ }^{\mathrm{TM}}$ structures. The greater moment of inertia of structures with low aspect ratio, such as those fabricated with SOIMUMPs ${ }^{\mathrm{TM}}$, minimises any unwanted out-of-plane displacement of the actuator arms as well as offers better resistance to the effects of in-plane residual stress, making such structures more suitable for in-plane directed thermal actuators [49]. It can also be observed from Figure 13b that Design Variant 3, which is composed of the stacked Poly-1 and Poly-2 layers, has the least out-of-plane displacement when compared to Design Variants 1 and 2, which confirms that lower aspect ratio structures minimise out-of-plane bending occurring as a result of residual stresses inherent in the fabrication process. Minimising the out-of-plane path deviation of the microgripper arms is an important requirement for the successful gripping of RBCs to ensure that the arm tips remain on the same plane as the RBC so that the latter can be successfully gripped during actuation.

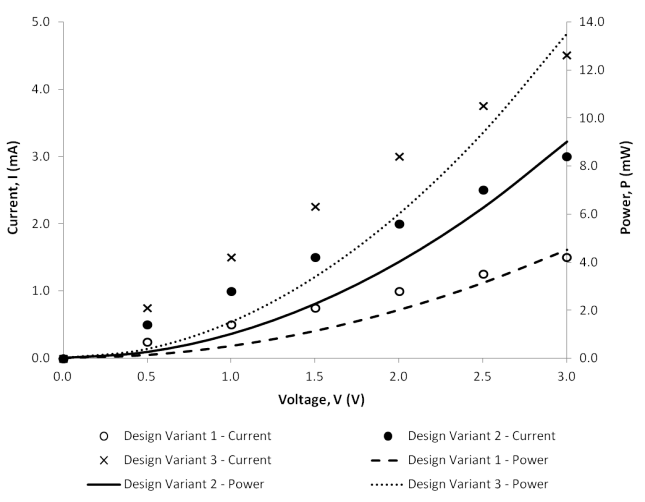

(a)

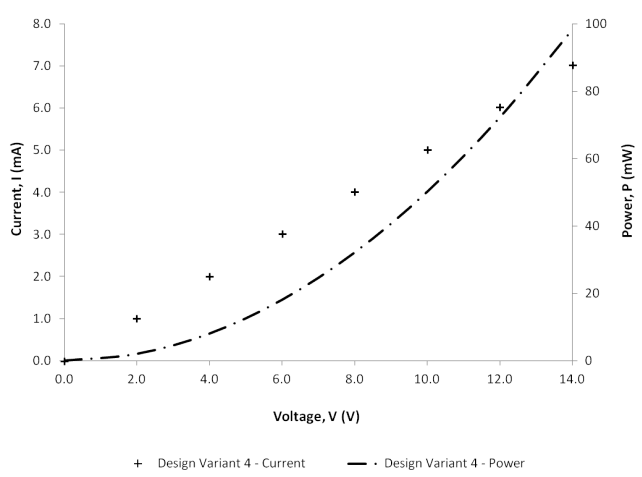

(b)

Figure 14. Numerical variation of the current and power dissipated with voltage across each arm of the microgripper structure for Design Variants 1-3 (a), and for Design Variant 4 (b).

Figure 15 shows the investigation of the developed maximum stresses within the hot and cold arm' microgripper structure. It can be observed that the maximum stresses are mainly located where the arms join the anchor pads, within the flexure component and at the connectors joining the hot and cold arms. The maximum Von Mises stress for Design Variants 1-4 ranges between $40 \mathrm{MPa}$ and $60 \mathrm{MPa}$ at full actuation voltage (3 V for Design Variants 1-3, $14 \mathrm{~V}$ for Design Variant 4). The ultimate tensile strength for polysilicon and SCS has been reported in literature as 2.9 GPa [50] and 2 GPa [51], respectively. This indicates that the simulated maximum stress values are by far within the limits of the allowable stress, concluding that maximum stresses and strains during the opening motion are not critical.

The analytical and numerical models of the PolyMUMPs ${ }^{\mathrm{TM}}$ structures (Design Variants 1-3) were validated through optical microscopy studies carried out under atmospheric pressure using the setup described in Section 5. Figure 16 shows the optical microscope images of Design 2 in the closed and actuated positions. The absolute gap opening between the arm tips when the microgripper is not actuated is $5 \mu \mathrm{m}$. The simulation and experimental measurement results of the absolute gap opening between the microgripper arm tips are compared for Design Variants 1-4 in Figure 17. Figure 17 demonstrates that the mean absolute gap openings obtained experimentally at $3 \mathrm{~V}$ are $9.5 \mu \mathrm{m}$ for Design 1, $12.5 \mu \mathrm{m}$ for Design 2 and $12 \mu \mathrm{m}$ for Design 3, and that the results predicted by the numerical models are in good agreement with the experimental results for Design Variants 1-3. The measured gap opening values confirm that Design Variants 1-3 are all suitable for the desired function of securing a RBC with an approximate $8 \mu \mathrm{m}$ diameter. 


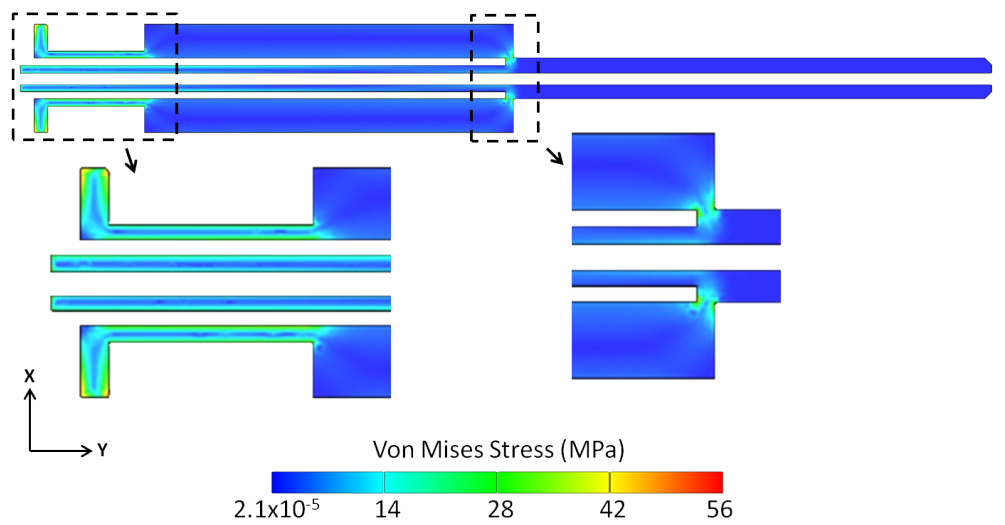

Figure 15. Von Mises stresses developed within the microgripper structure for Design Variant 1 at $3 \mathrm{~V}$ with inset images showing detailed views of the stresses where the arms join the anchor pads, within the flexure component and at the connectors joining the hot and cold arms.
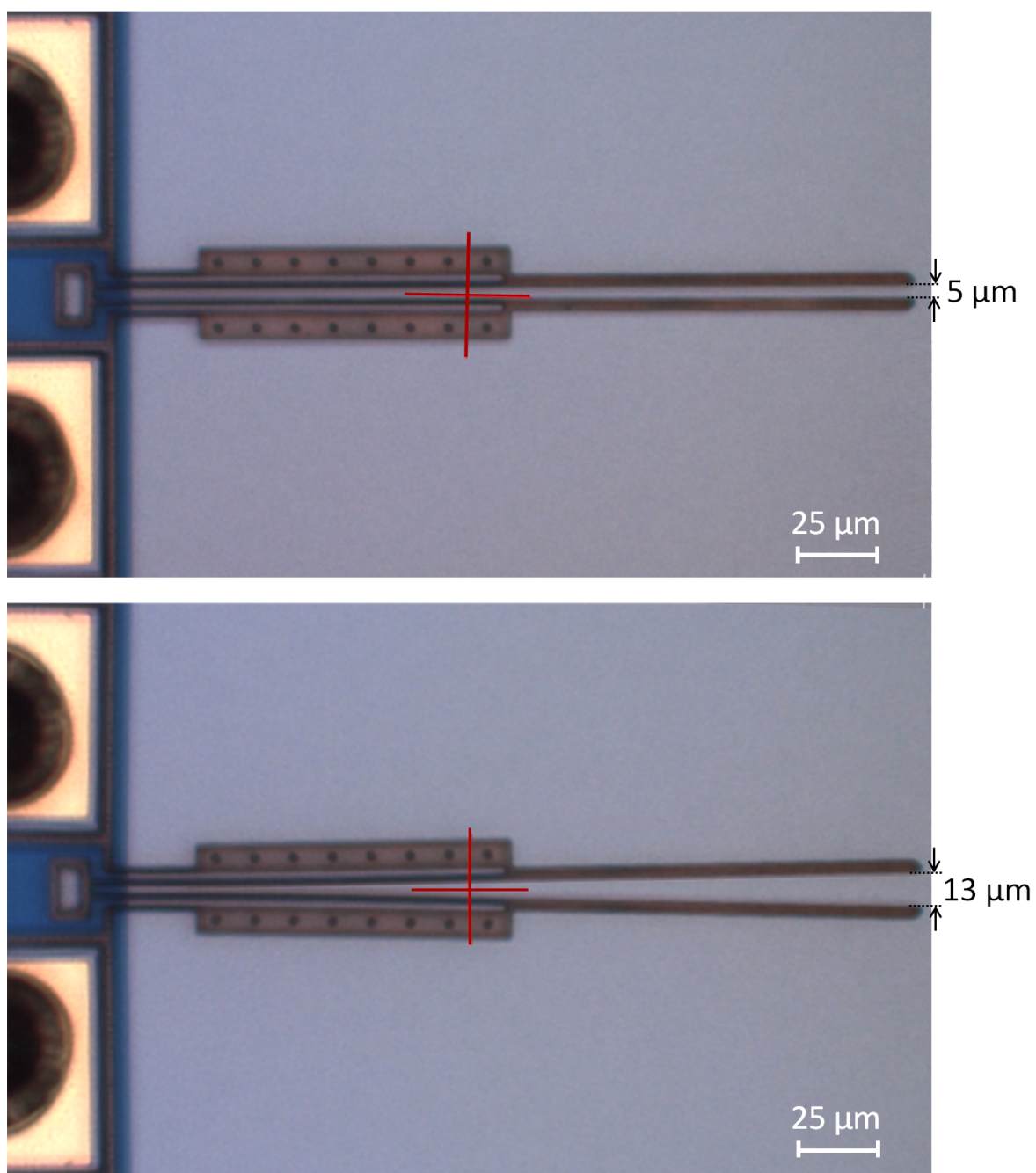

Figure 16. Images based on optical microscopy of one of the fabricated microgripper structures (Design 2) when not actuated (top), and when each arm is electrothermally actuated with $3 \mathrm{~V}$ (bottom). The pixel resolution of the vision system photographs is 1023 pixels (width) $\times 767$ pixels (height), and the marked values give the absolute gap openings between the microgripper arm tips. 


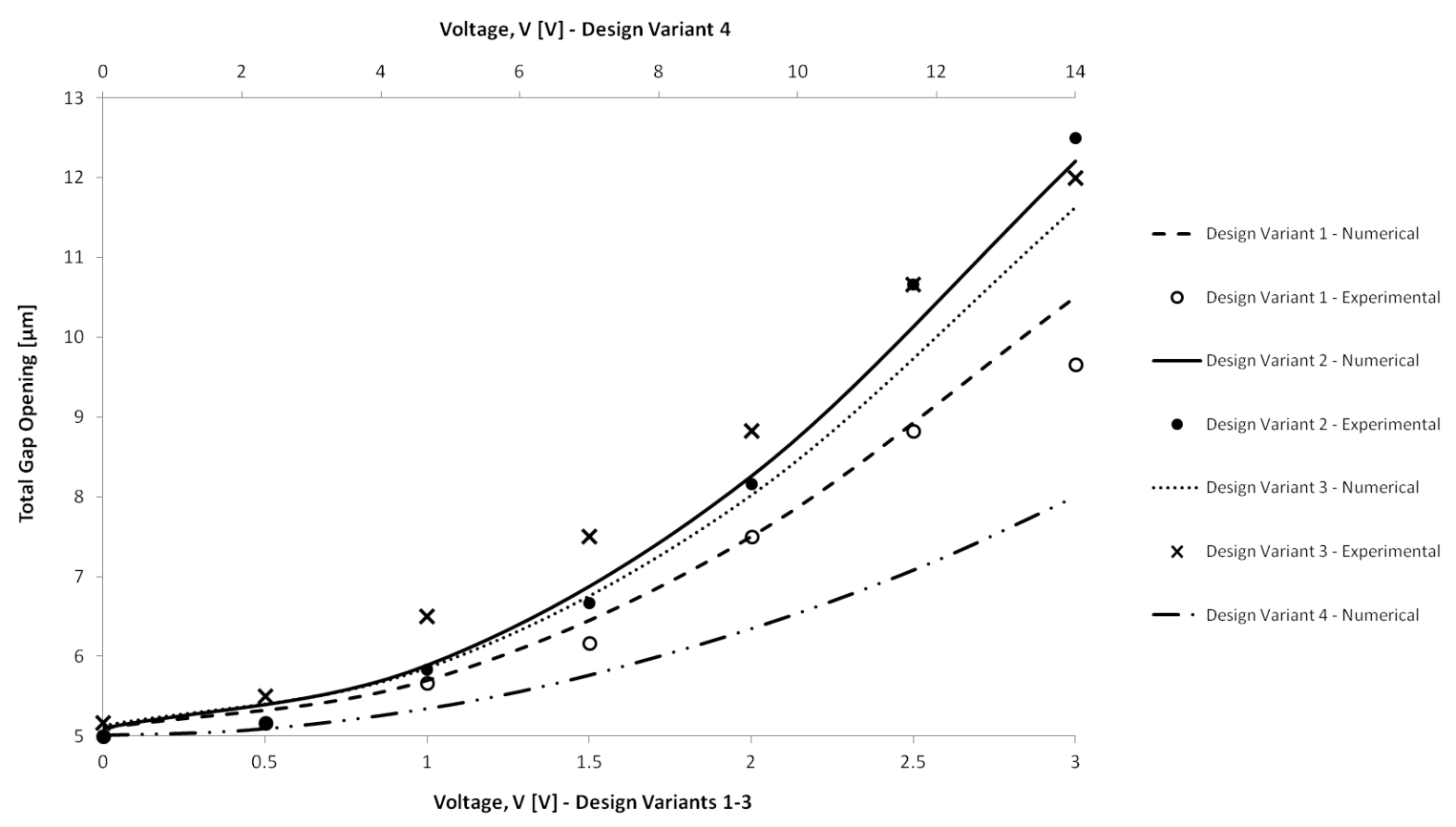

Figure 17. Comparison of the experimental and numerical results for the absolute gap opening between the arm tips of the studied microgripper design variants with applied voltage. Experimental (mean values) and numerical results are presented for Design Variants 1-3 while numerical results are shown for Design Variant 4. All design variants start from an absolute gap opening of $5 \mu \mathrm{m}$, which is the gap opening in the closed position.

\section{Conclusions}

This paper has presented four design variants of a horizontal electrothermally actuated MEMS microgripper that were developed for the micromanipulation and deformability study of RBCs using two commercially available fabrication technologies. Three microgripper design variants were achieved using the different stackable structural layers offered by the PolyMUMPS ${ }^{\mathrm{TM}}$ process, resulting in polysilicon structure thicknesses of $1.5 \mu \mathrm{m}, 2 \mu \mathrm{m}$ and $3.5 \mu \mathrm{m}$. The other microgripper design variant was achieved using the SOIMUMPs ${ }^{\mathrm{TM}}$ process resulting in a SCS structure with a $25 \mu \mathrm{m}$ thickness. The studied microgripper design variants have the same in-plane geometry and their main differences are due to the mechanical structure thickness, the air gap thickness or lack thereof, and the silicon type (polysilicon versus SCS), all of which are a result of the inherent characteristics of the specific fabrication technology used.

The electrothermomechanical performance, specifically the power dissipation, the temperature distribution, the lateral opening stroke and the out-of-plane deflection at the microgripper arm tips, were examined and compared for the microgripper design variants. Analytical calculations and FEA simulations with the commercial software package CoventorWare ${ }^{\circledR}$ were performed on the four microgripper design variants to investigate the steady-state response of the microgripper structures under electrothermal actuation. It could be observed that greater power is required for the SOIMUMPs ${ }^{\mathrm{TM}}$ structure to achieve a quantitatively similar temperature distribution and tip displacement to that obtained from the PolyMUMPs ${ }^{\mathrm{TM}}$ structures. Another interesting observation was that the microgripper arm tips of the SOIMUMPs ${ }^{\mathrm{TM}}$ structure, unlike PolyMUMPs ${ }^{\mathrm{TM}}$ structures, undergo a rise in temperature, making such a design less suitable for the safe manipulation of biological cells. However, SOIMUMPs ${ }^{\mathrm{TM}}$ structures have lower aspect ratios when compared to PolyMUMPs ${ }^{\mathrm{TM}}$ structures. This means that the greater moment of inertia of SOIMUMPs ${ }^{\mathrm{TM}}$ structures results in substantial out-of-plane stiffness, thus minimising any undesired out-of-plane path deviation and ensuring a more stable in-plane motion. The maximum stresses developed within the microgripper 
structure were also investigated for all the design variants and they were found to be well within the allowable material limits, confirming that the microgripper design variants are able to perform a stable opening and closing motion.

The three microgripper design variants based on the PolyMUMPs ${ }^{\mathrm{TM}}$ process were fabricated, and were subject to optical microscopy studies under atmospheric pressure. The tip displacement results from the actuation testing were found to comply with the analytical and numerical predictions, and all the design variants were also found to be in line with the design requirement to secure and characterise a RBC. However, it can be concluded that Design 3, which consists of two polysilicon stackable layers, resulting in a $3.5 \mu \mathrm{m}$ thick PolyMUMPs ${ }^{\mathrm{TM}}$ structure, best fulfills the desired function. This design experimentally achieved a sufficient mean gap opening of $12 \mu \mathrm{m}$ at $3 \mathrm{~V}$, while, at the same time, it was numerically found to limit the out-of-plane motion at the arm tips and to ensure room temperature conditions at the cell gripping zone.

Author Contributions: Conceptualisation, M.C., I.G., B.M., P.M. and N.S.; Formal analysis, M.C.; Funding acquisition, M.C., I.G., B.M., P.M. and N.S.; Investigation, M.C.; Methodology, M.C.; Project administration, M.C., I.G., B.M., P.M. and N.S.; Resources, M.C.; Supervision, I.G., B.M., P.M. and N.S.; Validation, M.C.; Visualisation, M.C.; Writing-Original draft, M.C.; Writing-Review and editing, M.C., I.G., B.M., P.M. and N.S.

Funding: The research work disclosed in this publication is funded by the Reach High Scholars ProgrammePost-Doctoral Grants. The grant is part-financed by the European Union, Operational Programme II-Cohesion Policy 2014-2020 Investing in human capital to create more opportunities and promote the wellbeing of societyEuropean Social Fund (ESF): grant number 254/15/05.

Acknowledgments: The technical help of Barnaby Portelli in the experimental activities performed at the Microelectronics Lab is acknowledged.

Conflicts of Interest: The authors declare no conflict of interest.

\section{References}

1. Zhang, R.; Chu, J.; Wang, H.; Chen, Z. A multipurpose electrothermal microgripper for biological micro-manipulation. Microsyst. Technol. 2013, 19, 89-97. [CrossRef]

2. Verotti, M.; Dochshanov, A.; Belfiore, N.P. Compliance synthesis of CSFH MEMS-based microgrippers. J. Mech. Des. Trans. ASME 2017, 139, 022301. [CrossRef]

3. Di Giamberardino, P.; Bagolini, A.; Bellutti, P.; Rudas, I.J.; Verotti, M.; Botta, F.; Belfiore, N.P. New MEMS tweezers for the viscoelastic characterization of soft materials at the microscale. Micromachines 2017, 9, 15. [CrossRef]

4. Kim, K.; Liu, X.; Zhang, Y.; Sun, Y. Nanonewton force-controlled manipulation of biological cells using a monolithic MEMS microgripper with two-axis force feedback. J. Micromech. Microeng. 2008, 18, 055013. [CrossRef]

5. Kim, K.; Liu, X.; Zhang, Y.; Cheng, J.; Yu, W.X.; Sun, Y. Elastic and viscoelastic characterization of microcapsules for drug delivery using a force-feedback MEMS microgripper. Biomed. Microdevices 2009, 11, 421-427. [CrossRef] [PubMed]

6. Solano, B.; Wood, D. Design and testing of a polymeric microgripper for cell manipulation. Microelectron. Eng. 2007, 84, 1219-1222. [CrossRef]

7. Iamoni, S.; Somà, A. Design of an electro-thermally actuated cell microgripper. Microsyst. Technol. 2014, 20, 869-877. [CrossRef]

8. Cecchi, R.; Verotti, M.; Capata, R.; Dochshanov, A.; Broggiato, G.B.; Crescenzi, R.; Balucani, M.; Natali, S.; Razzano, G.; Lucchese, F.; et al. Development of micro-grippers for tissue and cell manipulation with direct morphological comparison. Micromachines 2015, 6, 1710-1728. [CrossRef]

9. Potrich, C.; Lunelli, L.; Bagolini, A.; Bellutti, P.; Pederzolli, C.; Verotti, M.; Belfiore, N.P. Innovative silicon microgrippers for biomedical applications: Design, mechanical simulation and evaluation of protein fouling. Actuators 2018, 7, 12. [CrossRef]

10. Ivanova, K.; Ivanov, T.; Badar, A.; Volland, B.E.; Rangelow, I.W.; Andrijasevic, D.; Sümecz, F.; Fischer, S.; Spitzbart, M.; Brenner, W.; et al. Thermally driven microgripper as a tool for micro assembly. Microelectron. Eng. 2006, 83, 1393-1395. [CrossRef] 
11. Zhang, Y.; Chen, B.K.; Liu, X.; Sun, Y. Autonomous robotic pick-and-place of microobjects. IEEE Trans. Robot. 2010, 26, 200-207. [CrossRef]

12. Hamedi, M.; Vismeh, M.; Salimi, P. Design, analysis and fabrication of silicon microfixture with electrothermal microclamp cell. Microelectron. Eng. 2013, 111, 160-165. [CrossRef]

13. Verotti, M.; Dochshanov, A.; Belfiore, N.P. A comprehensive survey on microgrippers design: Mechanical structure. J. Mech. Des. 2017, 139, 060801. [CrossRef]

14. Jia, Y.; Xu, Q. MEMS microgripper actuators and sensors: The state-of-the-art survey. Recent Patents Mech. Eng. 2013, 6, 132-142. [CrossRef]

15. Yang, S.; Xu, Q. A review on actuation and sensing techniques for MEMS-based microgrippers. J. Micro-Bio Robot. 2017, 13, 1-14. [CrossRef]

16. Nguyen, N.-T.; Ho, S.-S.; Low, C.L. A polymeric microgripper with integrated thermal actuators. J. Microelectromech. Syst. 2004, 14, 969-974. [CrossRef]

17. Somà, A.; Iamoni, S.; Voicu, R.; Müller, R.; Al-Zandi, M.H.M.; Wang, C. Design and experimental testing of an electro-thermal microgripper for cell manipulation. Microsyst. Technol. 2018, 24, 1053-1060. [CrossRef]

18. Solano, B.; Merrell, J.; Gallant, A.; Wood, D. Modelling and experimental verification of heat dissipation mechanisms in an su-8 electrothermal microgripper. Microelectron. Eng. 2014, 124, 90-93. [CrossRef]

19. Al-Zandi, M.H.M.; Wang, C.; Voicu, R.; Müller, R. Measurement and characterisation of displacement and temperature of polymer based electrothermal microgrippers. Microsyst. Technol. 2018, 24, 379-387. [CrossRef]

20. Dochshanov, A.; Verotti, M.; Belfiore, N.P. A comprehensive survey on microgrippers design: Operational strategy. J. Mech. Des. 2017, 139, 070801. [CrossRef]

21. Kim, C.-J.; Pisano, A.P.; Muller, R.S. Silicon-processed overhanging microgripper. J. Microelectromech. Syst. 1992, 1, 31-36. [CrossRef]

22. Bagolini, A.; Ronchin, S.; Bellutti, P.; Chistè, M.; Verotti, M.; Belfiore, N.P. Fabrication of novel MEMS microgrippers by deep reactive ion etching with metal hard mask. J. Microelectromech. Syst. 2017, 26, 7920329. [CrossRef]

23. Wierzbicki, R.; Houston, K.; Heerlein, H.; Barth, W.; Debski, T.; Eisinberg, A.; Menciassi, A.; Carrozza, M.C.; Dario, P. Design and fabrication of an electrostatically driven microgripper for blood vessel manipulation. Microelectron. Eng. 2006, 83, 1651-1654. [CrossRef]

24. $\mathrm{Xu}, \mathrm{Q}$. Design, Fabrication, and testing of an MEMS microgripper with dual-axis force sensor. IEEE Sens. J. 2015, 15, 7150331. [CrossRef]

25. Cauchi, M.; Grech, I.; Mallia, B.; Mollicone, P.; Sammut, N. Analytical, Numerical and Experimental Study of a Horizontal Electrothermal MEMS Microgripper for the Deformability Characterisation of Human Red Blood Cells. Micromachines 2018, 9, 108. [CrossRef]

26. Feng, Y.-Y.; Chen, S.-J.; Hsieh, P.-H.; Chu, W.-T. Fabrication of an electro-thermal micro-gripper with elliptical cross-sections using silver-nickel composite ink. Sensors Actuators A Phys. 2016, 245, 106-112. [CrossRef]

27. Chronis, N.; Lee, L.P. Electrothermally activated SU-8 microgripper for single cell manipulation in solution. J. Microelectromech. Syst. 2005, 14, 857-863. [CrossRef]

28. Hannon, B.; Ruth, M. Malaria and Sickle Cell Anemia. In Dynamic Modeling of Diseases and Pests; Springer: New York, NY, USA, 2009; pp. 63-81.

29. Tomaiuolo, G. Biomechanical properties of red blood cells in health and disease towards microfluidics. Biomicrofluidics 2014, 8, 051501. [CrossRef] [PubMed]

30. Jeongho, K.; HoYoon, L.; Sehyun, S. Advances in the measurement of red blood cell deformability: A brief review. J. Cell. Biotechnol. 2015, 1, 63-79.

31. Alizadehrad, D.; Imai, Y.; Nakaaki, K.; Ishikawa, T.; Yamaguchi, T. Quantification of red blood cell deformation at high-hematocrit blood flow in microvessels. J. Biomech. 2012, 45, 2684-2689. [CrossRef] [PubMed]

32. Cauchi, M.; Mollicone, P.; Grech, I.; Mallia, B.; Sammut, N. Design and analysis of a MEMS-based electrothermal microgripper. In Proceedings of the International CAE Conference 2016, Parma, Italy, 17-18 October 2016.

33. Keoschkerjan, R.; Wurmus, H. A novel microgripper with parallel movement of gripping arms. In Proceedings of the Actuator 2002: 8th International Conference on New Actuators, Bremen, Germany, 10-12 June 2002; pp. 321-324.

34. Lobontiu, N. Compliant Mechanisms: Design of Flexure Hinges; CRC Press LLC: Boca Raton, FL, USA, 2003. 
35. Meng, Q.; Li, Y.; Xu, J. New empirical stiffness equations for corner-filleted flexure hinges. J. Mech. Sci. 2013, 4, 345-356. [CrossRef]

36. Figueredo, S. Heat transfer strategies for temperature sensitive components in vacuum environments. In Proceedings of the 16th International Conference of the European Society for Precision Engineering and Nanotechnology, Nottingham, UK, 30 May-3 June 2016.

37. Linß, S.; Schorr, P.; Zentner, L. General design equations for the rotational stiffness, maximal angular deflection and rotational precision of various notch flexure hinges. J. Mech. Sci. 2017, 8, 29-49. [CrossRef]

38. Belfiore, N.P.; Broggiato, G.; Verotti, M.; Balucani, M.; Crescenzi, R.; Bagolini, A.; Bellutti, P.; Boscardin, M. Simulation and construction of a MEMS CSFH based microgripper. Int. J. Mech. Control 2015, 16, 21-30.

39. Cowen, A.; Hardy, B.; Mahadevan, R.; Wilcenski, S. PolyMUMPs Design Handbook; MEMSCAP Inc.: Durham, NC, USA, 2011.

40. Cowen, A.; Hames, G.; Monk, D.; Wilcenski, S.; Hardy, B. SOIMUMPs Design Handbook; MEMSCAP Inc.: Durham, NC, USA, 2011.

41. Cho, S.W.; Chasiotis, I. Elastic properties and represenative volume element of polycrystalline silicon for MEMS. Exp. Mech. 2007, 47, 37-49.

42. Hopcroft, M.A.; Nix, W.D.; Kenny, T.W. What is the Young's Modulus of silicon? J. Microelectromech. Syst. 2010, 19, 229-238. [CrossRef]

43. Boyd, E.J.; Uttamchandani, D. Measurement of the anisotropy of Young's Modulus in single-crystal silicon. J. Microelectromech. Syst. 2012, 21, 243-249. [CrossRef]

44. Hickey, R.; Kujath, M.; Hubbard, T. Heat transfer analysis and optimization of two-beam microelectromechanical thermal actuators. J. Vac. Sci. Technol. Vac. Surf. Films 2002, 20, 971-974. [CrossRef]

45. Coutu, R.A.; LaFleur, R.S.; Walton, J.P.K.; Starman, L.A. Thermal management using MEMS bimorph cantilever beams. Exp. Mech. 2016, 56, 1293-1303. [CrossRef]

46. Zaitsev, B.N. Blood Cells Study. NT-MDT Spectrum Instruments; State Research Center of Virology and Biotechnology VECTOR: Koltsovo, Russia, 2015.

47. McConnell, A.D.; Uma, S.; Goodson, K.E. Thermal conductivity of doped polysilicon layers. J. Microelectromech. Syst. 2001, 10, 360-369. [CrossRef]

48. Kennedy, J.B.; Madugula, M.K.S. Elastic Analysis of Structures: Classical and Matrix Methods; Harper \& Row: New York, NY, USA, 1990; Chapters 7-9.

49. Miller, D.C.; Boyce, B.L.; Dugger, M.T.; Buchheit, T.E.; Gall, K. Characteristics of a commercially available silicon-on-insulator MEMS material. Sensors Actuators A Phys. 2007, 138, 130-144. [CrossRef]

50. Kapels, H.; Aigner, R.; Binder, J. Fracture strength and fatigue of polysilicon determined by a novel thermal actuator. IEEE Trans. Electron Dev. 2000, 47, 1522-1528. [CrossRef]

51. Tsuchiya, T. Tensile testing of silicon thin films. Fatigue Fracture Eng. Mater. Struct. 2005, 28, 665-674. [CrossRef] 